\title{
Lessons in Student Motivation
}

\author{
Errol Craig Sull, MA \\ Dell College Teacher of Excellence, 2005 \\ Columnist, USA Today
}

The tools students have at their ready to do well are really amazing: engaging, thorough, and colorful textbooks; the Internet, of course; faculty who know how to teach and offer a plethora of information; and seemingly endless possibilities for optimal learning environments. Yet with all these improved "mousetraps" there is one factor that, if missing, will keep each of these silent - and the student will learn little or naught: motivation. Indeed, if the student is not motivated to learn, and his or her motivation is not kept up throughout a course, there is little the student will take away from the course.

This - this motivation thing -- is something that we, as teachers, not only must try to maintain but have the power to create and build on.

What you are about to read is a collection of essays by varied faculty at Park

This - this motivation thing -- is something that we, as teachers, not only must try to maintain but have the power to create and build on.

University who offer solid, insightful, and tested approaches to developing and maintaining student motivation in the classroom. In many respects these can be seen as one of those "secrets" to teaching that all who enter the profession seek. But rather than secrets they are approaches to finding what works when it comes to student motivation that have been honed, sanded, and polished from many years of experience - and presented to you in a high gloss finish. Read them, absorb them, implement them: your classes, you, and your students will only benefit from them.

The lessons in effecting good student motivation from each faculty member in this journal did not come overnight, of course; many courses and years of teaching have allowed for "what really works" in his or her classes within that important realm of student motivation. The result: each has classes that run much smoother, have students who learn easier, and have involvement from their class members that is more enthusiastic throughout the length of each class. How wonderful to have so many offering so much on this one subject of motivation your "job" as the classroom mentor will be the easier for their efforts.

As you teach this or that course, it is imperative that you continue what these faculty are presenting: approaches, angles, tips, and "wows!" of creating and maintaining motivation in the classroom. Teaching is a profession that demands it morph with new technology, ever-changing student demographics and profiles, and the fluid nature of course structure; "how to" create and maintain motivation in the classroom is no different. As you come across something you believe is a bit different and works in this area, jot it down: for what you read in this collection will always remain as time-tested and solid approaches to "the motivation problem," but they can always use "buddies" to bolster motivation. No matter what form your contribution to this important issue of student motivation takes - comment to a colleague, departmental email, or a more formal presentation - be sure to share it. Doing so will only strengthen us as teachers - and only improve the student learning process.

Could we ask for any better outcome? No - for being a teacher we are inherently motivated to give our students the best possible in each class they take from us. And when we can do that just a tad better, well, how nice for all! 
Sull has taught online courses for more than 10 years. Currently an online composition instructor with Excelsior College, he has developed online teaching activities that are in use at more than 200 colleges and universities throughout the United States and Canada. A 2005 recipient of the Dell "Teacher of Excellence" award, Errol is a nationally recognized authority on developing and maintaining motivation with online students. The author of four books, including one on teaching writing to online students, he is currently finishing two more:" Pebbles: A Most Unusual Approach to Achieving Very Effective Writing" and "Shut Up \& Stop Being a Crybaby: How to Take Responsibility in An Increasingly Irresponsible World." He is a frequent speaker on motivation and has taught at the college level for 20 years. Additionally, he is a columnist for the online newsletter" Online Cl@ssroom, " has authored several articles on online teaching, conducts workshops on teaching online courses, and has either received or been nominated for various awards based on his teaching, both online and traditional classroom. Previously, Errol was cultural editor for Southern Living magazine and assistant editor of The National Enquirer. He earned a bachelor's degree in English from the State University of New York at Buffalo and a master's in English from Niagara University. 